Normalised particle radius

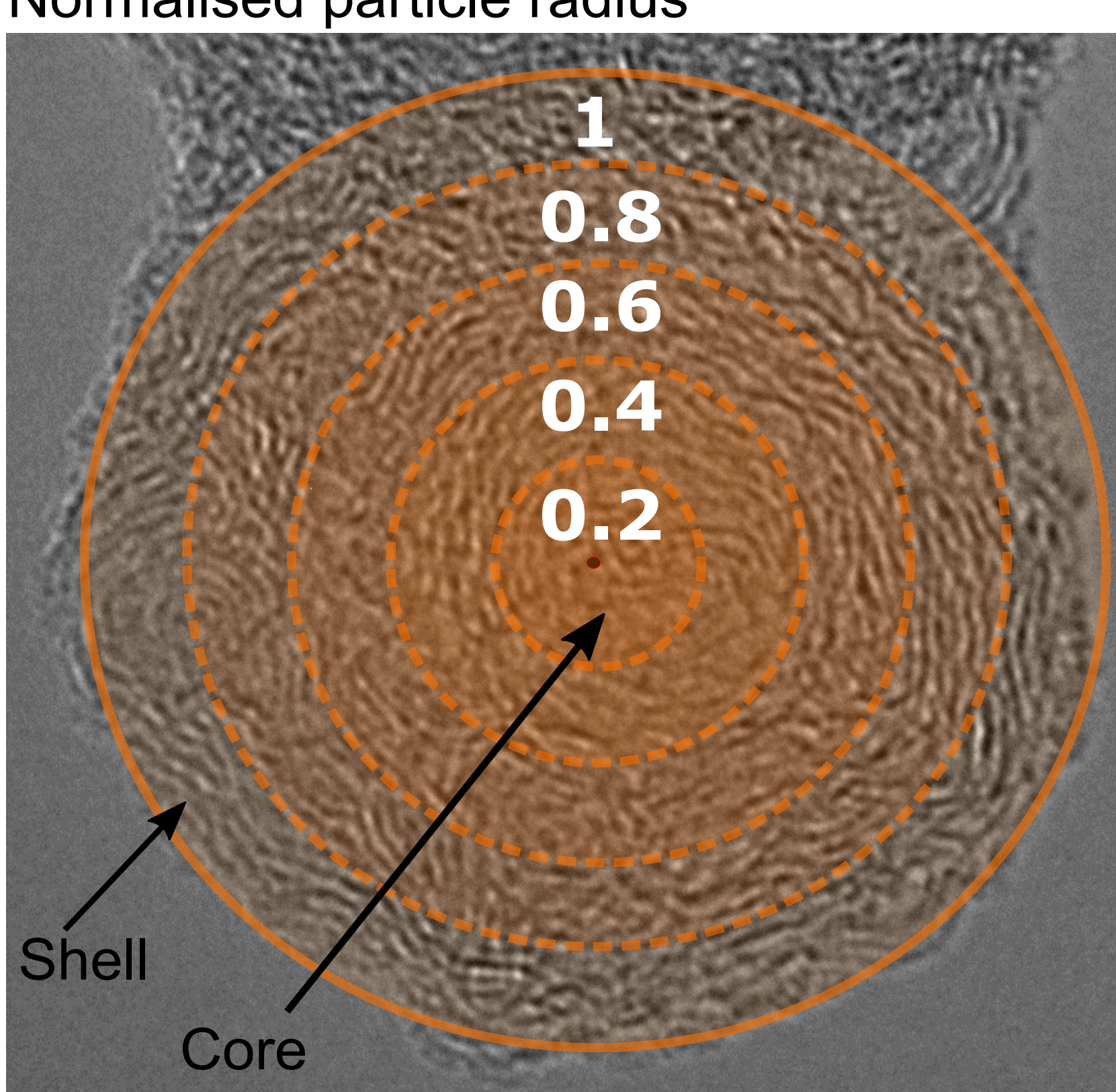

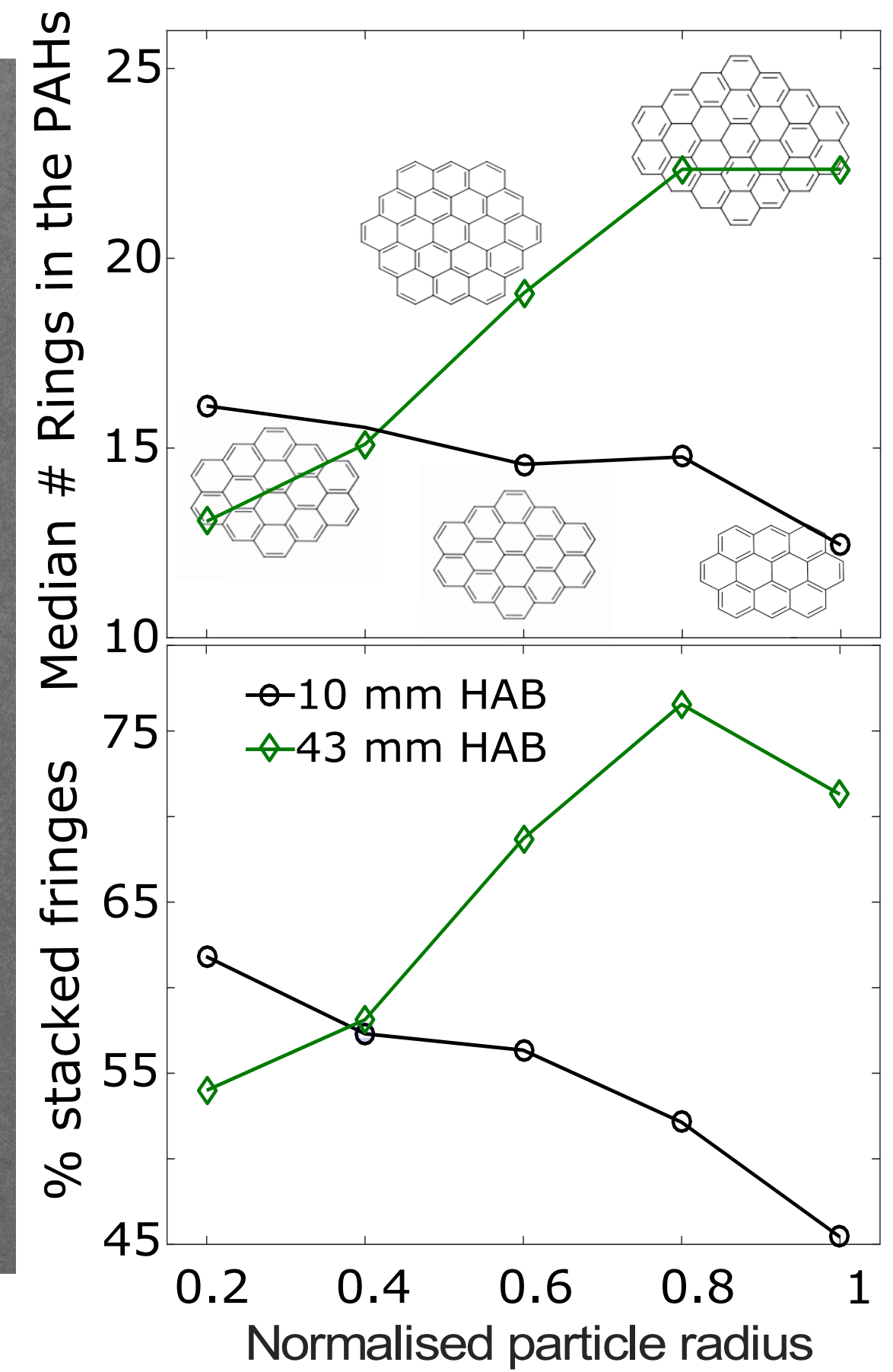

Mature soot

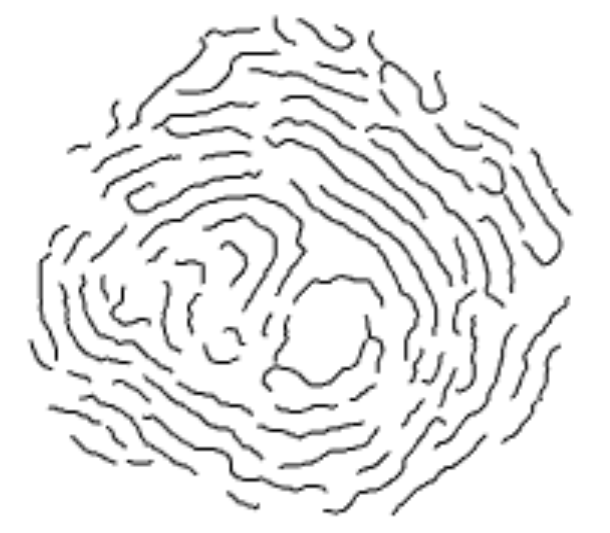

\section{Young soot}

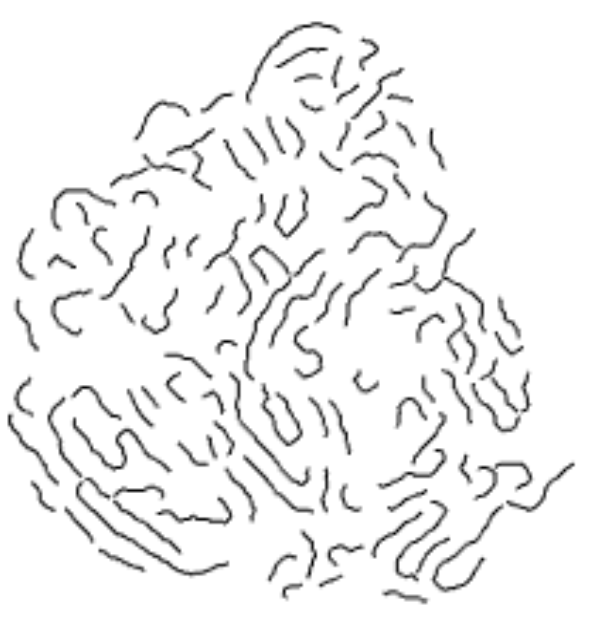




\title{
Internal structure of soot particles in a diffusion flame
}

\author{
Maria L. Botero ${ }^{\mathrm{a}, \mathrm{d}}$, Yuan Sheng ${ }^{\mathrm{b}, \mathrm{d}}$, Jethro Akroyd ${ }^{\mathrm{c}, \mathrm{d}}$, Jacob Martin ${ }^{\mathrm{c}, \mathrm{d}}$, \\ Jochen A.H. Dreyer, ${ }^{c, d}$, Wenming Yang ${ }^{a, d}$, Markus Kraft ${ }^{b, c, d, *}$ \\ ${ }^{a}$ Department of Mechanical Engineering, National University of Singapore, Singapore \\ ${ }^{b}$ School of Chemical and Biomedical Engineering, Nanyang Technological University, \\ Singapore \\ ${ }^{c}$ University of Cambridge, Chemical Engineering 8 Biotechnology, University of \\ Cambridge, United Kingdom \\ ${ }^{d}$ Cambridge Centre for Advanced Research and Education in Singapore (CARES), \\ Singapore
}

\section{Abstract}

The evolution of the internal structure of soot particles was studied in a coflow diffusion flame. Soot particles from the flame were imaged using high resolution transmission electron microscopy. An algorithm to quantify the nano-structure of the particles was extended to study the radial distribution of fringes within the particles. The approximate size of the molecules in the particles was calculated from the fringe lengths, assuming planar pericondensed PAHs. The molecules are slightly larger ( $\sim 16$ rings) and more stacked at the core than at the surface ( $\sim 12$ rings) of the youngest particles sampled, suggesting that the particles could be formed via the stabilisation of a nuclei of larger PAHs and condensation of smaller PAHs on their surface. In the lower-temperature region of the flame the molecules grow mainly at the surface of the particles, whereas the molecules in the core of the particles become less stacked and slightly smaller, indicating some degree of

\footnotetext{
${ }^{*}$ Corresponding Author

Email address: mk306@cam.ac.uk (Markus Kraft)
} 
nano-structural mobility. In the higher-temperature region of the flame, a graphitisation process takes place, with the development of a shell of longer ( $\sim 20$ rings), flatter and more compact molecules, and an immobilised amorphous core. At the tip of the flame the particles are oxidised, mainly through surface oxidation.

Keywords: soot nano-structure, polycyclic aromatic hydrocarbon, high resolution electron microscopy, lattice-fringe analysis

\section{Introduction}

Understanding the process of soot formation in combustion systems is of major importance, both to reduce its emission and the associated adverse effects on human health [1, 2] and the environment [3, 4], and to produce carbon-based products under controlled conditions for technological applications [5, 6, 7].

Transmission electron microscopy (TEM) has long been applied as a tool to study soot particles [8, 9, 10] and more recently, high resolution transmission electron microscopy (HRTEM) has enabled the detailed observation and quantification of the internal structure of the particles in the nano-scale [11, 12]. The morphology and nano-structure of soot can provide insight on the multiple processes involved in its formation, growth and oxidation [13].

Experimental studies have revealed that young soot particles $(<10 \mathrm{~nm})$ are disordered, consisting of short carbon layers with some curvature [14]. These young particles are thought to be formed from fast coalescence of precursor particles acting as a nuclei for the condensation of gas phase species [10, 15, 16, 17]. The nuclei (1-3 nm) are thought to be formed by the collision 
of polycyclic aromatic hydrocarbon (PAH) molecules [16, 18] and clusters of them [15, 19, 20], as revealed by HRTEM images of soot particles [21, 17. Mature soot primary particles exhibit a core-shell structure, consisting of a less structured core, potentially with multiple nuclei [14, 22], and a microcrystalline outer shell. Once a threshold temperature is reached an increase in the $\mathrm{C} / \mathrm{H}$ ratio and the degree of crystallinity is observed [17]. This increase in crystallinity is referred to here as graphitisation, and is indicated by the growth of crystallite plane and the decrease in the crystallite layer 'wrinkling' and inter-layer spacing [23, 24].

In addition to growth and graphitisation, oxidation plays an important role in many combustion systems. The reactivity of soot particles is important when considering their oxidation in particle filters for diesel engines [25, 26]. The oxidative reactivity of soot particles is greatly influenced by the internal structure of the particles [27, 28]. Particles that exhibit a higher graphitic order are harder to oxidise compared to less structured particles, due to the lower relative ratio of active sites and lower porosity inside the particle [25, 29].

HRTEM combined with fringe analysis has been increasingly used in recent years to study the mechanisms of soot formation and oxidation under different synthesis conditions [13, 30, 31, 32, 33, 34]. All of these studies evaluate fringe characteristics such as length, curvature, stacking and inter-planar distance in the soot aggregates. However, they do not take into account that these properties change from the particle core towards the surface, a key element in elucidating particle formation and oxidation. While fringe lengths have been plotted as a function of radial distance previously [35], this was 
done only for 1 particle. Full statistics of the radial distribution of fringes within the soot primary particles and their evolution with particle maturation have not yet been analysed. This can provide significant insight on the core-shell development as soot grows, matures and oxidises.

In this work we investigate the internal structure of soot primary particles at different stages of maturity. Soot is thermophoretically sampled from the centreline of an ethylene coflow diffusion flame at different heights above the burner (HAB). The soot samples were imaged in a HRTEM and analysed using lattice-fringe algorithm. The morphology and nano-structure of the particles are qualitatively and quantitatively evaluated. A new feature was added into our fringe analysis code [34] that allows us to map the fringes inside single spherical primary particles with reference to the particle centre. The radial distributions of the fringes length, tortuosity and inter-fringe spacing at different regions within the particles were used to investigate the different processes involved in their formation, growth and oxidation throughout the flame.

\section{Experimental methodology}

The burner used in this study was designed and built at Yale University 1 and was selected as one of the target systems for soot studies at the International Sooting Flame workshop ${ }^{2}$, The burner consists of a central

\footnotetext{
${ }^{1}$ Yale Coflow diffusion flames steady flame burner: http://guilford.eng yale.edu/ yalecoflowflames/steady_burner.html

${ }^{2}$ Laminar flames - Co-flow laminar diffusion flame: https://www.adelaide.edu.au/ cet/isfworkshop/data-sets/laminar/
} 
fuel tube with an outer diameter of 3/16" (11/64" inner diameter) and a concentric air co-flow tube with an inner diameter of 2.9". Herein, we report measurements of an atmospheric pressure ethylene flame diluted by nitrogen $\left(60 \% \mathrm{C}_{2} \mathrm{H}_{4}-40 \% \mathrm{~N}_{2}\right)$, which corresponds to the ISF Co-flow 3c flame ${ }^{2}$. The fuel, nitrogen and air flow rates are $134.7 \mathrm{ml} / \mathrm{min}( \pm 1 \%), 91.2 \mathrm{ml} / \mathrm{min}$ $( \pm 1 \%)$ and $89.1 \mathrm{l} / \mathrm{min}( \pm 2 \%)$ respectively, set by Vögtlin Red-Y digital flow controllers. The visible flame height is approximately $50 \mathrm{~mm}$ from the fuel tube exit. The burner is mounted on a motorized translational stage that moves it both horizontally and vertically. The flame temperature was measured with an uncoated R-type thermocouple with a wire diameter of $75 \mu \mathrm{m}$ and corrected for radiation losses as detailed in [36].

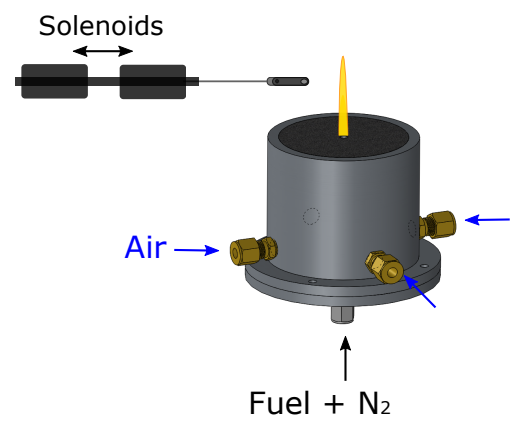

Figure 1: Representation of the burner ${ }^{1}$ and fast-insertion sampling.

Soot was sampled using a fast-insertion thermophoretic sampling system [34]. The sampling instrument consists two push-action solenoids (MCSMT3864S12STD, 12 VDC) mounted in front of each other and operating in opposite directions. The system is controlled by a programmable logic controller that triggers each solenoid with a lag time between them, this time being adjustable to change the residence time of the sampler in the flame. The sample holder is mounted on the plunger and consists of two metallic 
sheets used to hold the TEM grid. The design of the sampler was improved from our previous studies [34] according to the suggestions made by Lee and Yang [37] to minimise the flame disturbance: the aluminium sheet tongue inserted in the flame was trimmed to a width of $4 \mathrm{~mm}$ and thickness of $0.8 \mathrm{~mm}$. A schematic of the burner and sampling system is presented in Figure 1.

For all the sampling positions, the exposure of the grids was between 30-46 ms in order to minimise flame disturbance, contamination from other flame streamlines and maximise grid coverage. Contaminations of the sample by large aggregates from the wings was estimated to be $\sim 15 \%$. This effect is expected to be strongest at the lowest HAB (10 mm HAB), where the contamination from other streamlines should be more significant because of lower sample coverage. However, at lower HABs (10, 16, 20 and $25 \mathrm{~mm})$ it was possible to detect the contamination from the wings and eliminate it from the analysis; unfortunately, at larger HAB the contamination could not be isolated. Nevertheless, as HAB increases the differences in the aggregate and primary particle sizes between the wing and centreline are smaller [38]. At the top of the flame (43 and $49 \mathrm{~mm}$ ) the effect of contamination is considered negligible.

The TEM sampling grids were carbon-supported grids with a diameter of $3.05 \mathrm{~mm}$ (holey carbon film on 200 mesh copper grids for high resolution imaging, and carbon film on 400 mesh copper grid for low resolution imaging). The flame was sampled at the centreline at different HAB. At all HAB the probe was offset $0.2 \mathrm{~mm}$ radially in order to best capture the particles at the centreline, as suggested by the detailed flow simulations performed by Kempema and Long [38] on a similar flame. 
The samples were examined on a $200 \mathrm{kV}$ Jeol 2100F TEM using a $\mathrm{ZrO} / \mathrm{W}$ Schottky field emission gun. TEM images were taken with a magnification of $500,000 \times$ for fringe analysis, $30,000 \times$ for primary particle size and $10,000 \times$ for aggregate size measurement. The aggregate size was measured from the projected area, as the size of a sphere with equivalent projected area. An algorithm that automatically detects the aggregates in the TEM images was developed in MATLAB. The primary particle size was measured by manually fitting circles around the particles on each TEM image using MATLAB. More than 1000 primary particles and aggregates were analysed at each sampling position.

For lattice-fringe characterisation at least 25 images were analysed at each HAB with a total particle surveyed area between 7300 and $15200 \mathrm{~nm}^{2}$. To study the internal structure of spherical primary particles a minimum of 20 spherical-like particles were analysed at each HAB.

\section{Lattice-fringe analysis}

The TEM images were analysed with an in-house lattice fringe algorithm implemented in MATLAB and previously described in Botero et al. [34]. A region of interest (ROI) is selected for analysis and then the image contrast is improved with an automatic contrast enhancement (histogram equalisation), followed by a series of image transformations (gaussian low-pass filters and bottom hat transformation). The image is then binarised using Otsu's method. The binary image is skeletonised with a thinning algorithm, isolated pixels are eliminated and all fringes are screened to remove branching (this is a new feature explained below). Fringes below $0.483 \mathrm{~nm}$ (naphtha- 
lene) are discarded, and only fringes with a separation between $0.3345 \mathrm{~nm}$ (002 graphite distance) and $0.6 \mathrm{~nm}$ (after which Van der Waals forces are negligible) are considered to be stacked. Finally, the length and tortuosity ( $\tau$, fringe length divided by fringe end point distance) is calculated for all the detected fringes as well as the separation between stacked fringes (see Figures $2 \mathrm{a}$ and $\mathrm{b})$.

Some additional features were added to the previous algorithm:

- Branch trimming: fringes with branches are no longer eliminated or broken at the branch point. Each fringe that presents branching is analysed and the main backbone of the fringe is kept while separating the smaller branches. The new fringes generated in the branch separation are also analysed until all branching is removed.

- Fringe position with respect to a reference point: the algorithm allows the selection of a reference point in the image and calculates the distance of each detected fringe from the reference point. The distance is calculated as the average of the euclidean distance of each pixel in the fringe with respect to the reference point.

- Fringe distribution within a circular region (primary particle): the algorithm allows us to draw a circle around a specific region and estimate the fringes location with respect to the circle centre, as well as the circle diameter (Figure 20).

For particles that are nearly spherical, the location of the fringes with respect to the particle centre enables the study of the internal distribution of the fringes (length, tortuosity and spacing) within the particle. To study the 
internal particle structure at each HAB, at least 20 spherical-shaped primary particles were analysed. A total of 209 primary particles were analysed from 130 images. Given that each particle has a different diameter, the position of the fringes was normalised by the particle diameter, such that the radial distance to the particle centre varies from 0 to 1 , where 0 represents the particle centre and 1 represents the particle surface, as shown in Figure 2 dd. In this way, the fringe distribution from different particles can be compared with respect to their relative position within the particle. Other partitioning schemes were attempted, such as equal area shell, and similar trends were found, indicating that the radial partitioning was not influencing the resulting trends.
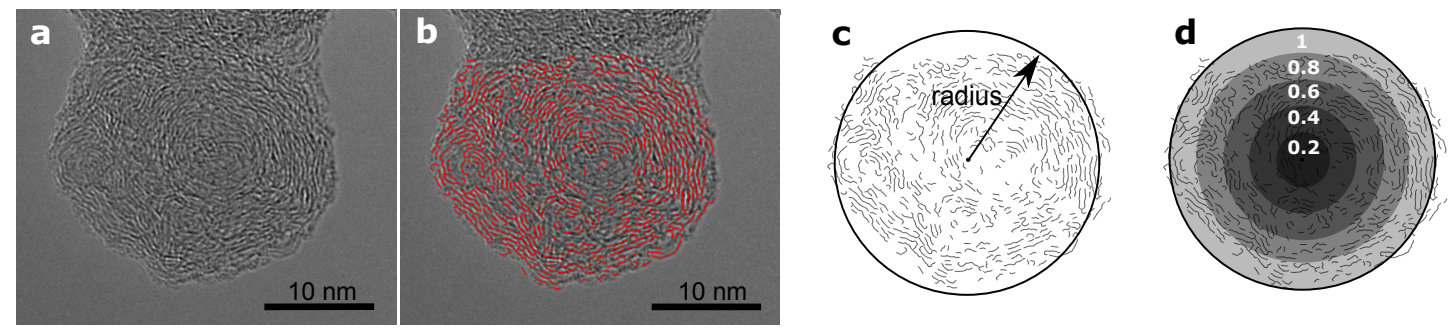

Figure 2: Schematic of the fringe mapping with respect to particle centre: (a) image of spherical-like soot primary particle, (b) overlayed fringe mapping, (c) mapped fringes and selection of a circle that outlines the particle, (d) different particle regions normalised by the particle radius.

\section{Results and Discussion}

A brief discussion of the soot morphology is presented to give an overview of the main particle processes occurring in the flame at different HAB. These processes are intrinsically related to the particle internal structure. A thor- 
ough discussion of the morphology of the particles in this flame is given elsewhere [39].

Figure 3 illustrates the evolution of soot morphology and nano-structure along the flame centreline. The left-hand panel shows the mean aggregate diameter $\left\langle\mathrm{D}_{\mathrm{p}}\right\rangle$ and mean primary particle diameter $\left\langle\mathrm{d}_{\mathrm{pp}}\right\rangle$ estimated from TEM micrographs. Soot is first detected at $10 \mathrm{~mm} \mathrm{HAB}$ and consists of small single particles about $12 \mathrm{~nm}$ in diameter with little evidence of aggregation. By $20 \mathrm{~mm}$ HAB the primary particle size grows to about $20 \mathrm{~nm}$ and still mostly single primaries are observed. At $25 \mathrm{~mm} \mathrm{HAB}$ there are signs of aggregation and aggregate sizes are almost double the size of the primary particles. At $31 \mathrm{~mm}$ HAB there is a sharp increase in the mean aggregate size $(\sim 100 \mathrm{~nm})$ and a slight decrease in the primary particle size, which suggests an increase in agglomeration and a decrease in surface growth and coalescence.

Towards the tip of the flame, the aggregate size remains fairly constant, whilst the primary particle size gradually decreases. This decrease occurs in a region (between 31 and $37 \mathrm{~mm}$ HAB) where oxygen diffusion to the centreline is not expected to be strong and where there is a transition to higher flame temperatures (as shown in Figure A.9. We have recently shown that the decrease in primary particle size in tis region could be due to the evaporation of condensed hydrocarbons on the surface of the parimary particles combined with the compaction induced by graphitisation [39]. The last hypothesis is consistent with the decrease in inter-fringe spacing and increase in the degree of stacking at those HABs, which will be discussed in the following sections. At the tip of the flame, both aggregate and primary particle size decreases 


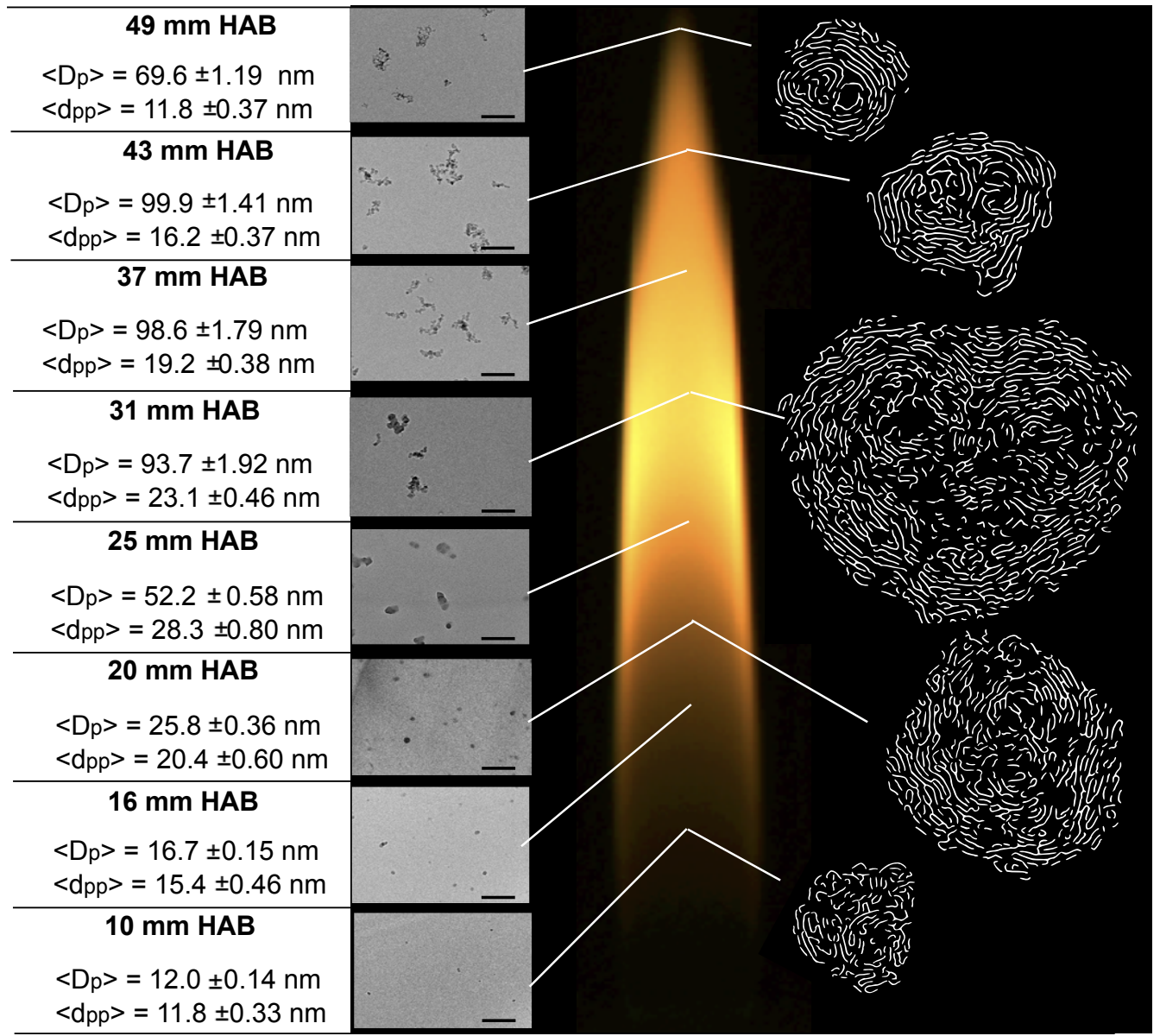

Figure 3: Soot morphology evolution in the flame. Left: mean aggregate size $\left\langle\mathrm{D}_{\mathrm{p}}\right\rangle$, mean primary particle size $\left\langle\mathrm{d}_{\mathrm{pp}}\right\rangle$ and representative TEM images of soot (scale bar of $200 \mathrm{~nm}$ ); Centre: flame image; Right: fringe mapping on a representative particle.

substantially, likely due to oxidation as reported previously in similar flames 36, 40, 41, 42.

The results of the lattice-fringe analysis were evaluated in two ways. First, the image analysis was performed on the aggregates irrespective of the particle morphology and all the mapped fringes were analysed together at each 
HAB to assess the general soot nano-structure, the results are discussed in Section 4.1. Second, for primary particles with spherical shape, the fringes were mapped and analysed with respect to the particle centre to assess the internal structure of the primary particles, the results are discussed in Section 4.2 .

To follow the size change of the molecules present in the soot particles as they travel through the flame, the fringe length values were converted into number of aromatic rings using Equation 1. This correlation between the number of aromatic rings $(M)$ and conjugation length $\left(L_{\mathrm{a}}\right)$ [3] was derived by Miller et al. from studies of optical band gaps of PAHs in flames [44, 45], and is limited to planar (aromatic structures containing only hexagonal rings), pericondensed, nearly-circular PAHs with $\mathrm{D}_{2 \mathrm{~h}}$ symmetry.

$$
\frac{\mathrm{M}^{1 / 2}}{5.8076}=\frac{\mathrm{L}_{\mathrm{a}}}{1.4787}
$$

Cross-linked aromatic compounds and PAHs with aliphatic side chains have been observed to be present in soot [46]. Also, fringe curvature has been detected in the soot particles, which is related to the presence of oddmembered, non-hexagonal rings and cross-linkage [47, 43]. However, the approximation that all the PAHs are planar, pericondensed, without aliphatic bonds, used by Miller et al. [45] in Equation 1, is considered a reasonable assumption as these PAHs are shown to be thermodynamically more stable at high temperatures [48].

\subsection{General nano-structure}

The distribution of the fringe length, tortuosity and spacing (for stacked fringes) were evaluated at each sampled HAB. A kernel density estimation 
is used to estimate the probability density function from the discrete observations. Representative HRTEM images of soot particles at each HAB can be seen in Figures A.10, A.11. The distribution of the number of aromatic rings in the PAHs in the aggregates analysed at each HAB is presented in Figure 4. In all cases, the PAH size distribution is similar and rather broad. The most abundant PAHs have approximately 7 aromatic rings (size of coronene), while a considerable amount of PAHs with 20 rings were observed. Notably, the assigned number of aromatic rings is less sensitive to the fringe length for larger PAHs. This is related to the assumptions made on the PAH structure discussed in the previous section. Adding one aromatic ring to a PAH with 7 rings (coronene) represents an increase of $0.046 \mathrm{~nm}$ in the fringe length, whereas for a 14 ring PAH (circumpyrene) the increase in fringe length is of $0.033 \mathrm{~nm}$. Given that the pixel size of the images is approximately $0.037 \mathrm{~nm}$, we expect the uncertainty in the PAH estimation to increase with the fringe length size, especially for PAHs with more than 15 rings.

In Figure 5 the distributions of fringe tortuosity and spacing are presented. The fringe tortuosity is a measure of the curvature of the fringes. The differences in fringe tortuosity are subtle along the flame, as shown in Figure 5a. Most of the fringes are almost straight $(\tau<1.15$, considered flat) or present a low degree of curvature $(1.15<\tau<1.35)$, indicating the presence of a maximum one or two pentagonal rings in the PAH [33].

The inter-fringe spacing distribution (Figure 5b) shows some differences between HAB. Notably at $10 \mathrm{~mm}$ HAB it seems that the stacked fringes have larger spacing, and at $43 \mathrm{~mm}$ HAB the smallest spacing. 


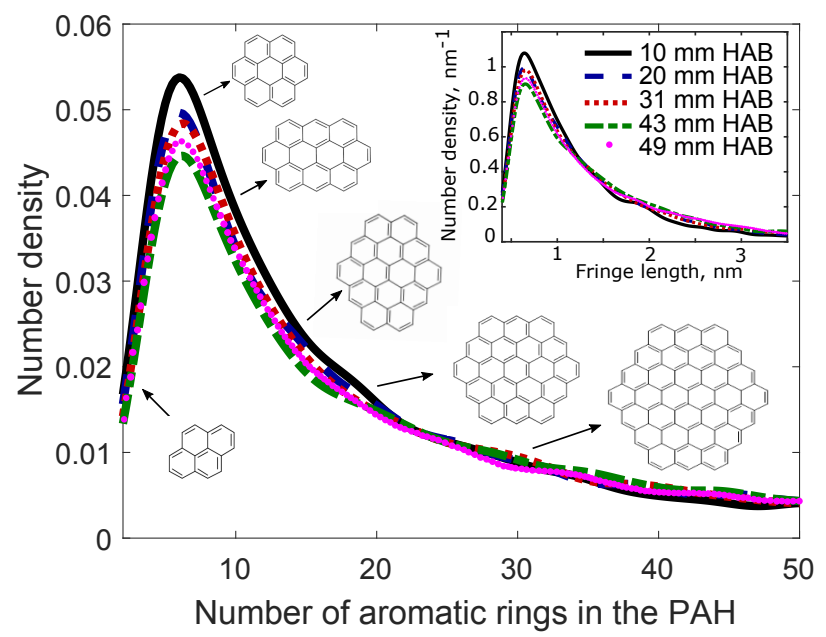

Figure 4: Kernel density of the number of aromatic rings at different HAB with an illustration of the PAH molecules of different sizes, (normal kernel, bandwidth of 2). Inset: corresponding kernel density of the fringe lengths, (normal kernel, bandwidth of 0.1).

Fringe statistics were calculated from the measured data in order to evaluate the differences in soot nano-structure along the flame (Figure 6). Given that the fringe length and tortuosity distributions are negatively skewed, the empirical median is calculated. For the inter-fringe spacing the mean was used instead.

A more graphitic structure develops as the soot particles travel though the flame, with an increase in the PAH size, a decrease in the inter-layer spacing (see Figure 6a and an increase in the planar structures (see Figure 6b). The particles are mainly formed of PAHs containing between 14 and 20 aromatic rings, either flat (40-50\%) or with low curvature ( 40\%). At the tip of the flame there is a decrease in PAH size and an increase in the interfringe spacing, which is attributed to oxidation. At the lowest HAB, PAHs with approximately 14 aromatic rings (size of circumpyrene) are encountered, 


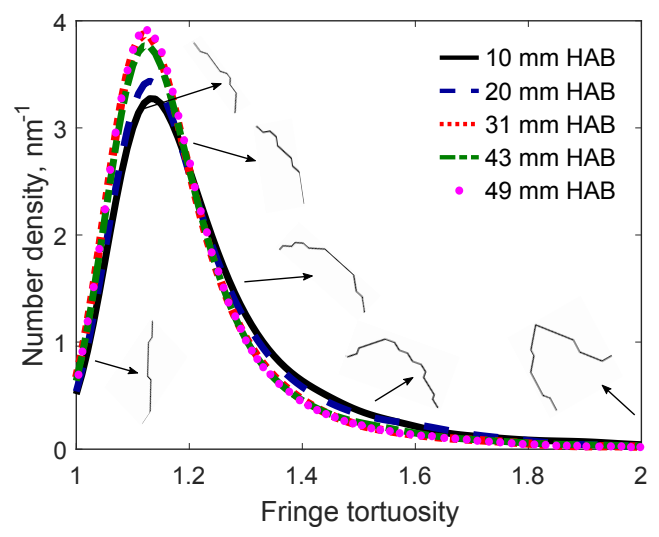

(a)

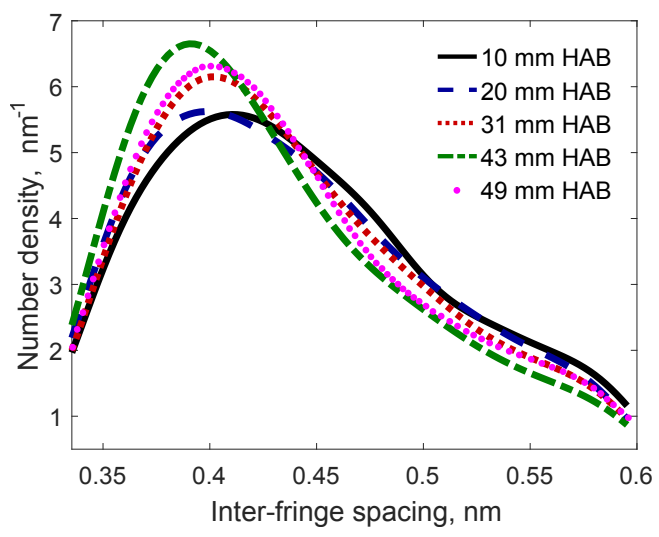

(b)

Figure 5: Kernel density of (a) fringe tortuosity with and schematic of representative fringes (normal kernel, bandwidth of 0.05) and (b) inter-fringe spacing (normal kernel, bandwidth of 0.02) at different HAB. Fringes with $\tau<1.15$ are considered flat, $1.15<$ $\tau<1.35$ slightly curved, and $\tau>1.35$ highly curved. Error bars correspond to the standard error.

which is consistent with values reported in similar flames [43, 44].

\subsection{Evolution of the internal structure of primary particles in the flame}

Images showing the evolution of soot nano-structure in the flame (right side of Figure 3 reveal that as the particle travels along the centreline, a core-shell structure develops, which is indicative of graphitisation processes [49. In order to investigate the changes in the internal structure of the particles at different maturity stages, the fringes were divided into five regions based on the normalised radius from the centre $(0.0-0.2,0.2-0.4,0.4-0.6,0.6-$ $0.8,0.8-1.0)$. The median number of aromatic rings in the PAHs, the fringe tortuosity, as well as the mean inter-fringe spacing and the percentage of stacked fringes were calculated for each region at different HABs, and are 


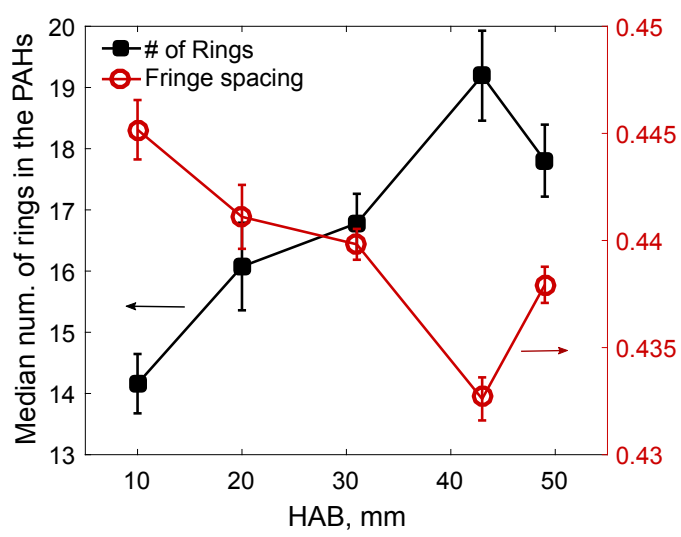

(a)

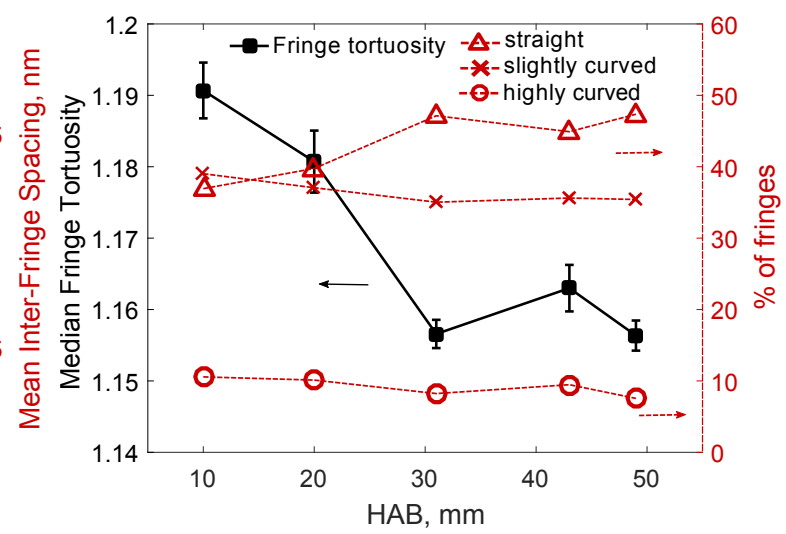

(b)

Figure 6: Evolution of the fringe parameters with HAB: (a) Median number of aromatic rings in a $\mathrm{PAH}$ (left axis) and mean inter-fringe spacing (right axis); (b) Median fringe tortuosity (left axis) and percentage of fringes with high, low and no curvature (right axis). The error bars correspond to the standard error.

presented in Figure 7 .

At the lowest HAB $(10 \mathrm{~mm})$ the young primary particles have poor structural ordering without a distinctive core-shell structure. The median PAH size is larger at the particle core ( $\sim 16$ aromatic rings), and it decreases slightly towards the particle shell ( $\sim 13$ aromatic rings), as shown in Figure 7a. The PAHs have a larger tortuosity (Figure $7 \mathbf{b}$ ) and are poorly stacked, with the largest inter-fringe spacing (Figure 7c and the lowest percentages of stacked fringes (Figure $\mathbf{7 d}$ ), particularly in the particle outer region (normalised radius of $0.6-0.8$ and $0.8-1.0$ ). The observed tortuosity indicates the presence of curved particles. It has been shown that the curvature is likely to be due to the inclusion of 5-membered rings and results in a flexoelectric dipole moment [50], which could have interesting implications 


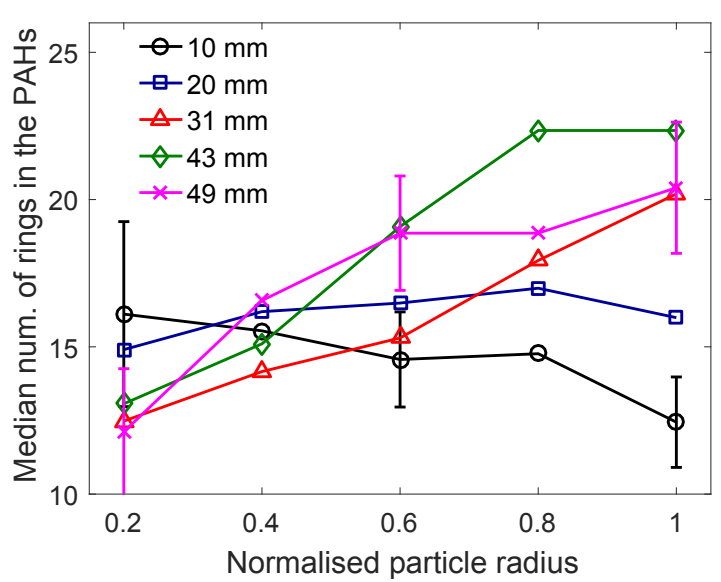

(a)

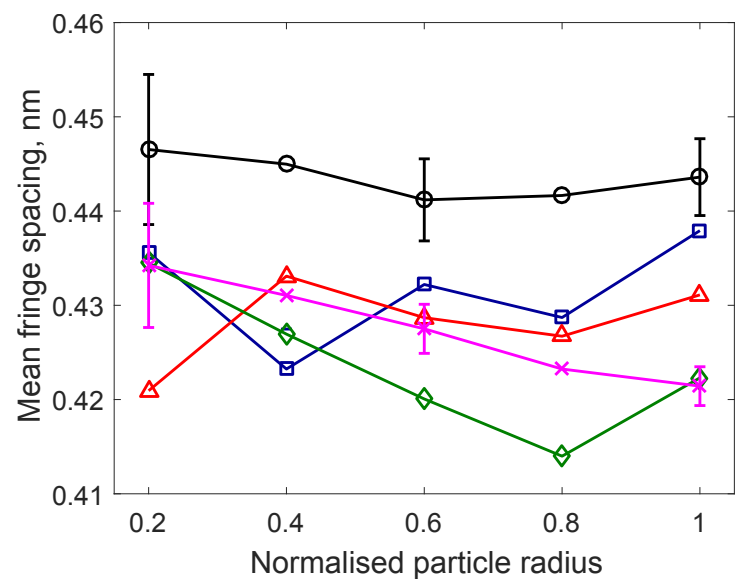

(c)

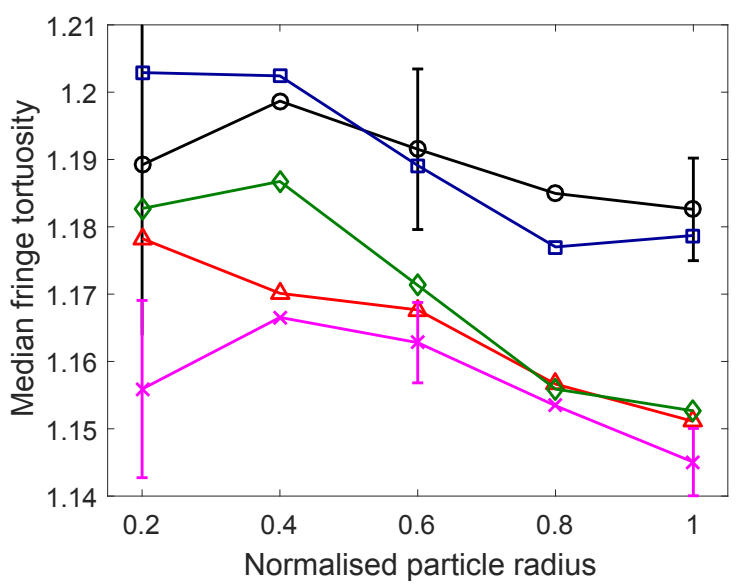

(b)

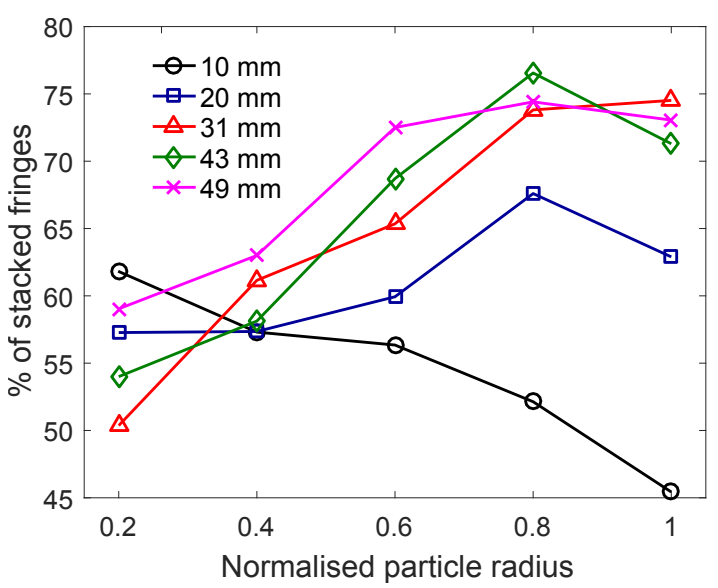

(d)

Figure 7: Fringe characteristics at different regions within the particle. A normalised particle radius of 0 corresponds to the particle centre and 1 to the particle surface. (a) number of aromatic rings in the PAHs, (b) fringe tortuosity, (c) fringe spacing and (d) percentage of stacked fringes. The error bars correspond to the standard error, selected values are presented to avoid cluttering and are representative for all the data points.

on the stabilisation of soot nuclei.

These results suggest that the transition from precursor particles to small 
primary particles $(\sim 12 \mathrm{~nm})$ could be a result of the formation of stable nuclei of larger and relatively more stacked PAHs, followed by the subsequent condensation of smaller PAHs on their surface. The existence of young particles with a graphitic core and an amorphous outer shell has been previously observed by di Stasio [10], who named them 'elementary particles'. He suggested these particles could be formed by the coagulation of nucleus doublets. This implies that coagulation and fast rounding of these particles (by condensation of smaller PAHs) could also be a reason for the appearance of larger molecules at the core. Different internal structures were observed in the young soot particles as shown in Figure 8, some without clear evidence of an internal nucleus, and some exhibiting fringes oriented around single or multiple points inside the particle.
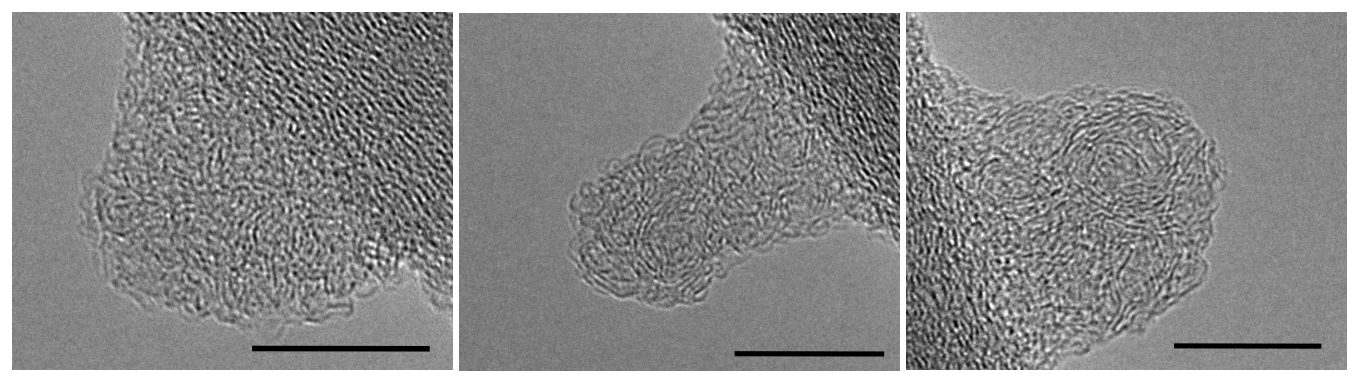

Figure 8: Representative HRTEM images of soot particles sampled at $10 \mathrm{~mm}$ HAB. The scale bar corresponds to $10 \mathrm{~nm}$.

At $20 \mathrm{~mm}$ HAB no shell has yet formed around the primary particles. The fringe analysis shows that the PAHs grow slightly in size at the middle and outer regions of the particles. They show a decrease in the inter-fringe spacing and considerable increase in the percentage of stacked fringes, mainly at the particle outer regions. As the primary particle travels further through the 
flame, there is a substantial increase of the PAH sizes mainly at the surface but progressively also towards the centre of the particles. By $43 \mathrm{~mm}$ HAB a thick shell has developed (between 0.6-0.8 and 0.8-1.0 normalised radius), with median PAH sizes of more than 20 aromatic rings, almost $80 \%$ of them stacked. Simultaneously, the percentage of flat fringes at the particle shell increased from $39 \%$ at $10 \mathrm{~mm} \mathrm{HAB}$ to $48 \%$ at $43 \mathrm{~mm} \mathrm{HAB}$. Overall, the inter-fringe spacing decreases with particle growth and maturation with a larger degree of stacking mainly between the middle and outer region of the particle (0.6-1.0 normalised radius). These results together with the flame temperature profile, presented in Figure A.9, indicate that the graphitisation of the soot particles starts at high temperature regions of the flame $(>1500 \mathrm{~K})$ [13, 24, 51, 52] and achieves its highest stage at $43 \mathrm{~mm}$ HAB, where the maximum temperature is reached (1945 K).

Notably, in the first half of the flame (from 10 to $30 \mathrm{~mm} \mathrm{HAB}$ ) at the innermost region of the particles (0.0-0.2 normalised radius), there is a decrease of the degree of stacking (from $62 \%$ to $50 \%$ ) and to a minor extent of the median PAH size (from 16 to 12 aromatic rings), as shown in Figures $\mathbf{7 a}, \mathbf{7 d}$. At flame temperatures, this could suggest some degree of nano-structural mobility at the core of the particles that would allow the re-arrangement of the molecules [53], with the smaller PAHs concentrating in the core. This is in agreement with a molecular dynamics study of clusters of pyrene and coronene, where Chen et al. [20] concluded that the individual PAH molecules within incipient soot particle are highly mobile at flame temperatures. At the top of the flame (from 30 to $43 \mathrm{~mm} \mathrm{HAB}$ ), the degree of stacking increases and the median size of the PAHs at the innermost region 
of the particle is almost constant (around 12 aromatic rings), suggesting the molecules are locked or immobilised at the core of the particle (Figure $7 \mathbf{d}$ ).

At the tip of the flame (49 mm HAB) the PAH sizes decrease mainly at the particle shell and an increase in the inter-fringe spacing is observed. This suggests that the oxidation process mainly occurs at the particle shell, even though these molecules should be less reactive than those at the inner regions of the particle due to their higher structural order [29, 54]. The internal burning of the primary particles is subject to a large extent to the penetration of oxidising species to the internal surface of the particle giving access to the edges of internal crystallite surfaces [25]. In the present case there seems to be poor oxygen diffusion to the centre of primary particle [55], hence no internal burning. Interestingly, at the particle core the tortuosity of the fringes decreases and their degree of stacking increases. This could be due to thermally-driven graphitisation given the high temperatures and the possible lack of internal oxidation [13, 56].

\section{Conclusions}

The evolution of the internal nano-sturcture of soot particles in a diffusion flame was studied using HRTEM and lattice-fringe analysis. For the first time, the fringe distribution with respect to the primary particle radius was evaluated and used to investigate the different processes involved in the formation and growth of soot nano-particles.

The nascent particles have low nano-sturctural order without a core-shell type of structure. The sizes of the PAH molecules inside these particles are similar, mainly between 12 and 16 aromatic rings. The core of these particles 
have slightly bigger PAHs with a higher degree of stacking compared to the outer regions, suggesting they could be formed from the condensation of smaller PAH on the surface of a flame-stabilised nuclei of larger PAHs.

As the primary particles travel through the first half of the flame (10 to $25 \mathrm{~mm} \mathrm{HAB}$ ), where temperatures are relatively lower, particle growth is dominated by coalescence and PAH condensation from the gas phase. The PAHs in the particle surface become larger, less curved and more stacked. Meanwhile, the PAHs in the innermost region of the particles are slightly smaller and less stacked, indicating some degree of nano-structural mobility at the core of the particles at flame temperatures that allows the diffusion of smaller PAHs to the core.

Towards the top of the flame (25 to $43 \mathrm{~mm} \mathrm{HAB}$ ) the primary particles cease to grow and starts to shrink. A graphitisation process takes place indicated by the increase of PAH size and degree of order. This process starts from the perimeter and expands towards the middle off the particle, developing a core-shell structure with a progressively thicker shell of flatter and more compact PAHs and an immobilised amorphous core.

Finally, at the tip of the flame (49 mm HAB), the aggregate and primary particle size decreases. The PAH size and fringe stacking is reduced only at near the surface of the particles, accompanied by an increase in the inter-fringe spacing, which indicates that soot oxidation in this flame predominantly occurs on the surface of the soot primary particle. At the core of these particles, the PAH size and inter-fringe spacing remains unchanged, but the fringes are less curved and have a higher degree of stacking, indicating graphitisation probably due to the high temperatures and low penetration of 
oxidising species.

\section{Acknowledgments}

This project is funded by the National Research Foundation (NRF), Prime Minister's Office, Singapore under its Campus for Research Excellence and Technological Enterprise (CREATE) programme. 


\section{References}

[1] Atkinson, R.W., Kang, S., Anderson, H.R., Mills, I.C., Walton, H.A.. Epidemiological time series studies of PM2.5 and daily mortality and hospital admissions: a systematic review and meta-analysis. Thorax 2014;69(7):660-665. doi:10.1136/thoraxjnl-2013-204492.

[2] Møller, P., Folkmann, J.K., Forchhammer, L., Bräuner, E.V., Danielsen, P.H., Risom, L., et al. Air pollution, oxidative damage to dna, and carcinogenesis. Cancer Letters 2008;266(1):84 - 97. doi: 10.1016/j.canlet.2008.02.030. Oxidative Stress and Carcinogenesis Special Issue.

[3] Jacobson, M.Z.. Strong radiative heating due to the mixing state of black carbon in atmospheric aerosols. Nature 2001;409(1):695 - 697. doi:10.1038/35055518.

[4] Bond, T.C., Doherty, S.J., Fahey, D.W., Forster, P.M., T., , DeAngelo, B.J., et al. Bounding the role of black carbon in the climate system: A scientific assessment. Journal of Geophysical Research: Atmospheres 2013;118(11):5380-5552. doi:10.1002/jgrd.50171.

[5] Lawrence, K., Baker, C.L., James, T.D., Bull, S.D., Lawrence, R., Mitchels, J.M., et al. Functionalized carbon nanoparticles, blacks and soots as electron transfer building blocks and conduits. Chemistry An Asian Journal 2013;9(5):1226-1241. doi:10.1002/asia.201301657.

[6] Wang, H., Xu, H., Jia, W., Ren, S.. Functionalized carbon black nanoparticles used for separation of emulsified oil from oily wastewater. 
Journal of Dispersion Science and Technology 2018;39(4):497-506. doi: 10.1080/01932691.2017.1298040.

[7] Mykhailiv, O., Zubyk, H., Plonska-Brzezinska, M.E.. Carbon nanoonions: Unique carbon nanostructures with fascinating properties and their potential applications. Inorganica Chimica Acta 2017;468:49 - 66 . doi:10.1016/j.ica.2017.07.021. Special Volume: Protagonists in Chemistry Dedicated to Professor Luis Echegoyen.

[8] Dobbins, R.A., Megaridis, C.M.. Morphology of flame-generated soot as determined by thermophoretic sampling. Langmuir 1987;3(2):254259. doi:10.1021/la00074a019.

[9] Vander Wal, R.L.. A TEM methodology for the study of soot particle structure. Combustion Science and Technology 1997;126(1-6):333-351. doi:10.1080/00102209708935680.

[10] di Stasio, S.. Electron microscopy evidence of aggregation under three different size scales for soot nanoparticles in flame. Carbon 2001;39(1):109 - 118. doi:10.1016/S0008-6223(00)00099-3.

[11] Shim, H.S., Hurt, R.H., Yang, N.Y.. A methodology for analysis of 002 lattice fringe images and its application to combustion-derived carbons. Carbon 2000;38(1):29 - 45. doi:10.1016/S0008-6223(99)00096-2.

[12] Yehliu, K., Vander Wal, R.L., Boehman, A.L.. Development of an HRTEM image analysis method to quantify carbon nanostructure. Combustion and Flame 2011;158(9):1837 - 1851. doi:10.1016/j. combustflame.2011.01.009. 
[13] Vander Wal, R.L., Tomasek, A.J.. Soot nanostructure: dependence upon synthesis conditions. Combustion and Flame 2004;136(1-2):129 140. doi:10.1016/j.combustflame.2003.09.008.

[14] Ishiguro, T., Takatori, Y., Akihama, K.. Microstructure of diesel soot particles probed by electron microscopy: First observation of inner core and outer shell. Combustion and Flame 1997;108(1-2):231 - 234. doi:10.1016/S0010-2180(96)00206-4.

[15] Frenklach, M.. Reaction mechanism of soot formation in flames. Physical Chemistry Chemical Physics 2002;4:2028-2037. doi:10.1039/ B110045A.

[16] Miller, J.H.. Aromatic excimers: evidence for polynuclear aromatic hydrocarbon condensation in flames. Proceedings of the Combustion Institute 2005;30(1):1381 - 1388. doi:10.1016/j.proci.2004.08.192.

[17] Hayashida, K., Nagaoka, S., Ishitani, H.. Growth and oxidation of graphitic crystallites in soot particles within a laminar diffusion flame. Fuel 2014;128(0):148 - 154. doi:10.1016/j.fuel.2014.03.008.

[18] Hayashida, K., Mogi, T., Amagai, K., Arai, M.. Growth characteristics of polycyclic aromatic hydrocarbons in dimethyl ether diffusion flame. Fuel 2011;90(2):493 - 498. doi:10.1016/j.fuel.2010.10.012.

[19] Totton, T.S., Chakrabarti, D., Misquitta, A.J., Sander, M., Wales, D.J., Kraft, M.. Modelling the internal structure of nascent soot particles. Combustion and Flame 2010;157(5):909 - 914. doi: 10.1016/j.combustflame.2009.11.013. 
[20] Chen, D., Totton, T.S., Akroyd, J., Mosbach, S., Kraft, M.. Sizedependent melting of polycyclic aromatic hydrocarbon nano-clusters: A molecular dynamics study. Carbon 2014;67(0):79 - 91. doi:10.1016/j. carbon.2013.09.058.

[21] Vander Wal, R.L., Bryg, V.M., Huang, C.H.. Aircraft engine particulate matter: Macro- micro- and nanostructure by HRTEM and chemistry by XPS. Combustion and Flame 2014;161(2):602 - 611. doi: 10.1016/j.combustflame.2013.09.003.

[22] Chen, H., Dobbins, R.. Crystallogenesis of particles formed in hydrocarbon combustion. Combustion Science and Technology 2000;159(1):109-128. doi:10.1080/00102200008935779.

[23] Oberlin, A.. Carbonization and graphitization. Carbon 1984;22(6):521 - 541. doi:10.1016/0008-6223(84)90086-1.

[24] Emmerich, F.. Evolution with heat treatment of crystallinity in carbons. Carbon 1995;33(12):1709 - 1715. doi:10.1016/0008-6223(95)00127-8.

[25] Vander Wal, R.L., Yezerets, A., Currier, N.W., Kim, D.H., Wang, C.M.. HRTEM study of diesel soot collected from diesel particulate filters. Carbon 2007;45(1):70 - 77. doi:10.1016/j.carbon.2006.08.005.

[26] Lapuerta, M., Oliva, F., Agudelo, J.R., Boehman, A.L.. Effect of fuel on the soot nanostructure and consequences on loading and regeneration of diesel particulate filters. Combustion and Flame 2012;159(2):844 853. doi:10.1016/j.combustflame.2011.09.003. 
[27] Jung, H., Kittelson, D.B., Zachariah, M.R.. Kinetics and visualization of soot oxidation using transmission electron microscopy. Combustion and Flame 2004;136(4):445 - 456. doi:10.1016/j.combustflame.2003.10. 013.

[28] Seong, H.J., Boehman, A.L.. Studies of soot oxidative reactivity using a diffusion flame burner. Combustion and Flame 2012;159(5):1864 1875. doi:10.1016/j.combustflame.2012.01.009.

[29] Jaramillo, I.C., Gaddam, C.K., Vander Wal, R.L., Lighty, J.S.. Effect of nanostructure, oxidative pressure and extent of oxidation on model carbon reactivity. Combustion and Flame 2015;162(5):1848 - 1856. doi: 10.1016/j.combustflame.2014.12.006.

[30] Vander Wal, R.L., Mueller, C.J.. Initial investigation of effects of fuel oxygenation on nanostructure of soot from a direct-injection diesel engine. Energy \& Fuels 2006;20(6):2364-2369. doi:10.1021/ef060201+.

[31] Alfé, M., Apicella, B., Rouzaud, J.N., Tregrossi, A., Ciajolo, A.. The effect of temperature on soot properties in premixed methane flames. Combustion and Flame 2010;157(10):1959 - 1965. doi:10.1016/ j.combustflame.2010.02.007.

[32] Yehliu, K., Vander Wal, R.L., Armas, O., Boehman, A.L.. Impact of fuel formulation on the nanostructure and reactivity of diesel soot. Combustion and Flame 2012;159(12):3597 - 3606. doi:10.1016/j. combustflame.2012.07.004. 
[33] Apicella, B., Pre, P., Alfé, M., Ciajolo, A., Gargiulo, V., Russo, C., et al. Soot nanostructure evolution in premixed flames by high resolution electron transmission microscopy (HRTEM). Proceedings of the Combustion Institute 2015;35(2):1895 - 1902. doi:10.1016/j.proci. 2014.06.121.

[34] Botero, M.L., Chen, D., González-Calera, S., Jefferson, D., Kraft, M.. HRTEM evaluation of soot particles produced by the non-premixed combustion of liquid fuels. Carbon 2016;96:459-473. doi: 10.1016/j.carbon.2015.09.077.

[35] Teini, P.D., Karwat, D.M., Atreya, A.. Observations of nascent soot: Molecular deposition and particle morphology. Combustion and Flame 2011;158(10):2045 - 2055. doi:10.1016/j.combustflame.2011.03.005.

[36] Botero, M.L., Mosbach, S., Akroyd, J., Kraft, M.. Sooting tendency of surrogates for the aromatic fractions of diesel and gasoline in a wick-fed diffusion flame. Fuel 2015;153:31 - 39. doi:10.1016/j.fuel.2015.02.108.

[37] Lee, J., Yang, S.Y.. A study of stability and vibration for particle sampling probes. International Journal of Mechanical Sciences 2013;76(Supplement C):152 - 157. doi:10.1016/j.ijmecsci.2013.09.013.

[38] Kempema, N.J., Long, M.B.. Combined optical and TEM investigations for a detailed characterization of soot aggregate properties in a laminar coflow diffusion flame. Combustion and Flame 2016;164:373 385. doi:10.1016/j.combustflame.2015.12.001. 
[39] Botero, M.L., Eaves, N., Dreyer, J.A., Sheng, Y., Akroyd, J., Yang, W., et al. Experimental and numerical study of the evolution of soot primary particles in a diffusion flame. Proceedings of the Combustion Institute 2018; doi:https://doi.org/10.1016/j.proci.2018.06.185.

[40] Botero, M.L., Mosbach, S., Kraft, M.. Sooting tendency of paraffin components of diesel and gasoline in diffusion flames. Fuel 2014;126:8 15. doi:10.1016/j.fuel.2014.02.005.

[41] Botero, M.L., Mosbach, S., Kraft, M.. Sooting tendency and particle size distributions of n-heptane/toluene mixtures burned in a wick-fed diffusion flame. Fuel 2016;169:111 - 119. doi:https://doi.org/10.1016/j. fuel.2015.12.014.

[42] Li, Z., Qiu, L., Cheng, X., Li, Y., Wu, H.. The evolution of soot morphology and nanostructure in laminar diffusion flame of surrogate fuels for diesel. Fuel 2018;211(Supplement C):517 - 528. doi:10.1016/j. fuel.2017.09.036.

[43] Botero, M.L., Adkins, E.M., González-Calera, S., Miller, H., Kraft, M.. PAH structure analysis of soot in a non-premixed flame using high-resolution transmission electron microscopy and optical band gap analysis. Combustion and Flame 2016;164:250-258. doi:10.1016/j. combustflame.2015.11.022.

[44] Adkins, E.M., Houston, J.H.. Extinction measurements for optical band gap determination of soot in a series of nitrogen-diluted ethy- 
lene/air non-premixed flames. Physical Chemistry Chemical Physics 2015;17:2686-2695. doi:10.1039/C4CP04452E.

[45] Miller, J.H., Herdman, J.D., Green, C.D., Webster, E.M.. Experimental and computational determinations of optical band gaps for $\mathrm{PAH}$ and soot in a $\mathrm{N}_{2}$ - diluted, ethylene/air non-premixed flame. Proceedings of the Combustion Institute 2013;34(2):3669 - 3675. doi: 10.1016/j.proci.2012.05.054.

[46] Schulz, F., Commodo, M., Kaiser, K., Falco, G.D., Minutolo, P., Meyer, G., et al. Insights into incipient soot formation by atomic force microscopy. Proceedings of the Combustion Institute 2018;doi: https://doi.org/10.1016/j.proci.2018.06.100.

[47] Wang, C., Huddle, T., Huang, C.H., Zhu, W., Vander Wal, R.L., Lester, E.H., et al. Improved quantification of curvature in highresolution transmission electron microscopy lattice fringe micrographs of soots. Carbon 2017;117:174 - 181. doi:10.1016/j.carbon.2017.02.059.

[48] Stein, S.E., Fahr, A.. High-temperature stabilities of hydrocarbons. The Journal of Physical Chemistry 1985;89(17):3714-3725. doi:10.1021/ j100263a027.

[49] Alfé, M., Apicella, B., Barbella, R., Rouzaud, J.N., Tregrossi, A., Ciajolo, A.. Structure-property relationship in nanostructures of young and mature soot in premixed flames. Proceedings of the Combustion Institute 2009;32(1):697 - 704. doi:10.1016/j.proci.2008.06.193. 
[50] Martin, J.W., Slavchov, R.I., Yapp, E.K.Y., Akroyd, J., Mosbach, S., Kraft, M.. The Polarization of Polycyclic Aromatic Hydrocarbons Curved by Pentagon Incorporation: The Role of the Flexoelectric Dipole. The Journal of Physical Chemistry C 2017;121(48):27154-27163.

[51] Oberlin, A.. High-resolution TEM studies of carbonizaionand graphitization. In: Chemistry and Physics of Carbon; vol. 22. P.A. Thrower; 1989.

[52] Kholghy, M., Saffaripour, M., Yip, C., Thomson, M.J.. The evolution of soot morphology in a laminar coflow diffusion flame of a surrogate for jet a-1. Combustion and Flame 2013;160(10):2119 - 2130. doi:10.1016/ j.combustflame.2013.04.008.

[53] Hurt, R.H., Crawford, G.P., Shim, H.S.. Equilibrium nanostructure of primary soot particles. Proceedings of the Combustion Institute 2000;28(2):2539 - 2546. doi:10.1016/S0082-0784(00)80670-0.

[54] Müller, J.O., Su, D., Jentoft, R., Kröhnert, J., Jentoft, F., Schlögl, R.. Morphology-controlled reactivity of carbonaceous materials towards oxidation. Catalysis Today 2005;102-103:259 - 265. doi: 10.1016/j.cattod.2005.02.025. 1st International Symposium on Carbon for Catalysis.

[55] Chen, D., Akroyd, J., Mosbach, S., Kraft, M.. Surface reactivity of polycyclic aromatic hydrocarbon clusters. Proceedings of the Combustion Institute 2015;35(2):1811 - 1818. doi:10.1016/j.proci.2014.06.140. 
[56] Gaddam, C.K., Huang, C.H., Vander Wal, R.L.. Quantification of nano-scale carbon structure by HRTEM and lattice fringe analysis. Pattern Recognition Letters 2016;76:90 - 97. doi:10.1016/j.patrec.2015.08. 028. Special Issue on Skeletonization and its Application. 


\section{Appendix A. Supplemental Material}

Appendix A.1. Temperature profile

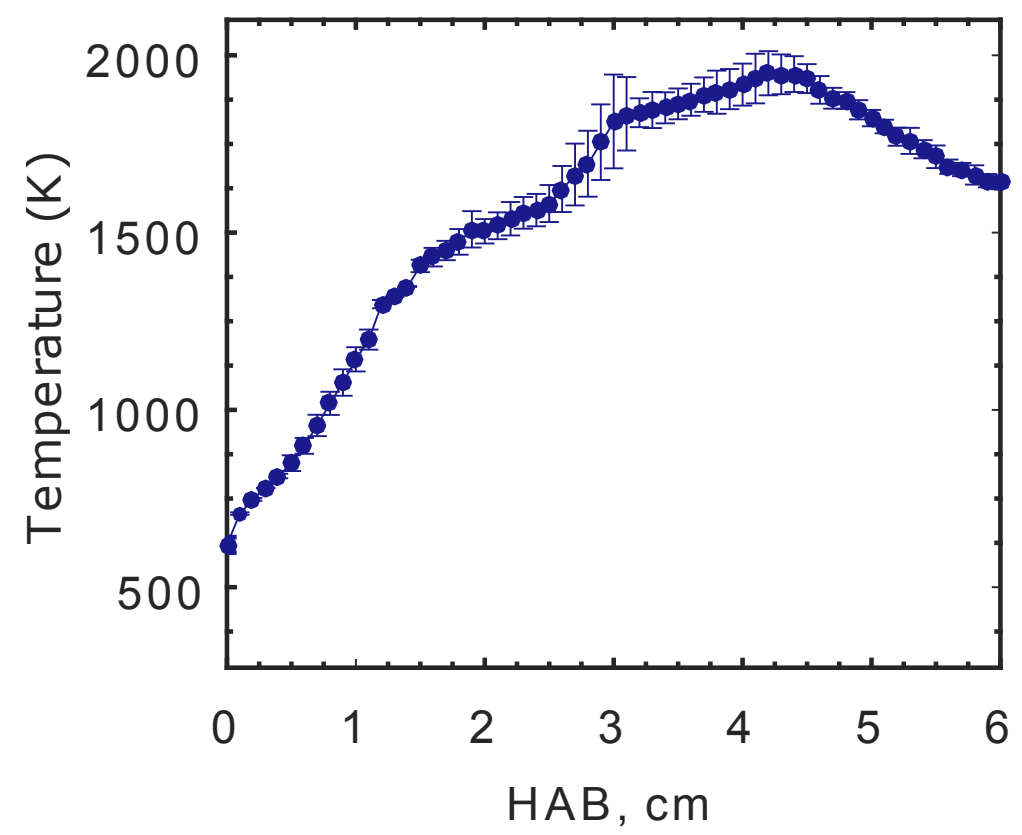

Figure A.9: Temperature profile along the centreline of the flame. 
Appendix A.2. HRTEM images at each HAB
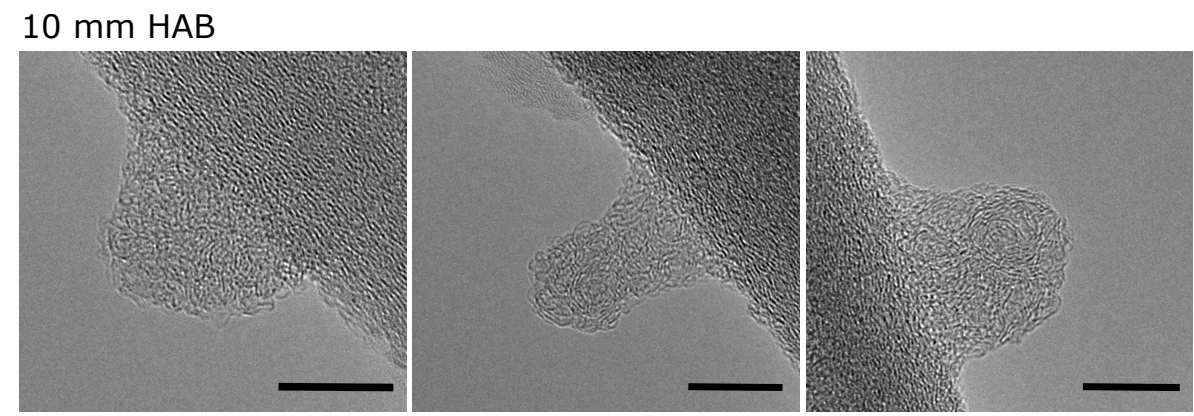

\section{$16 \mathrm{~mm} H A B$}
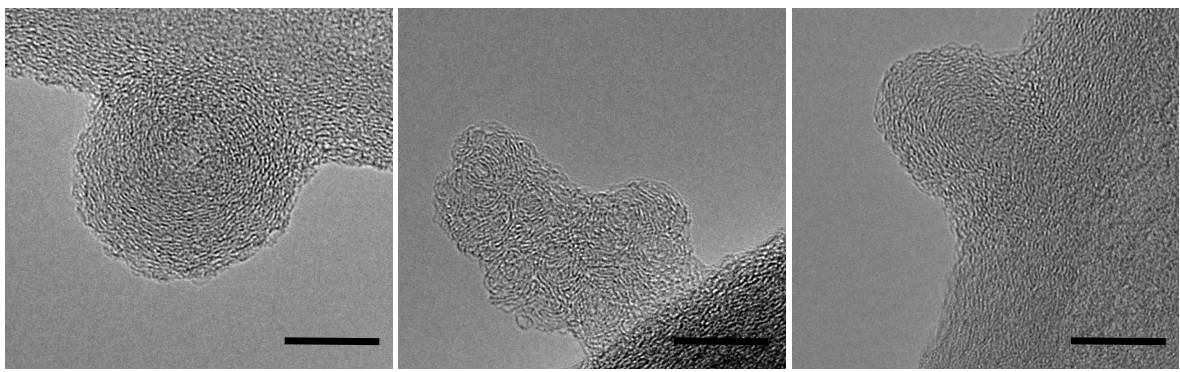

$20 \mathrm{~mm} \mathrm{HAB}$
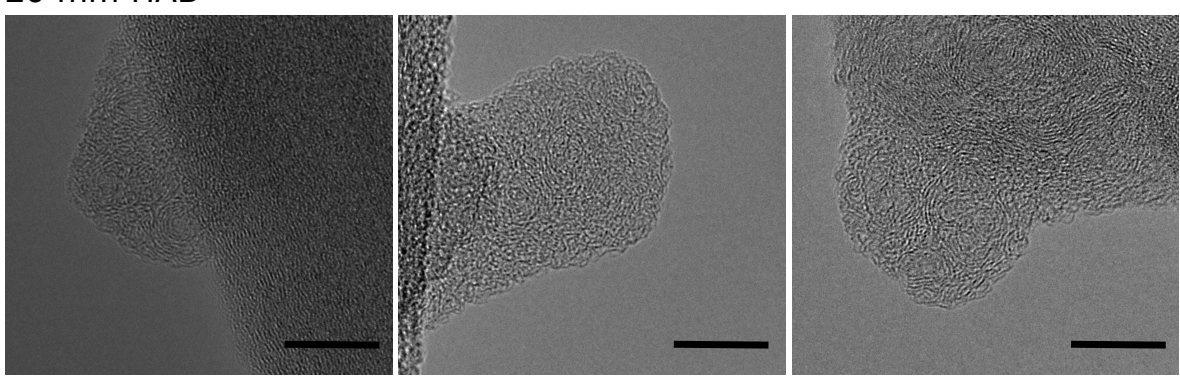

\section{$25 \mathrm{~mm} H A B$}
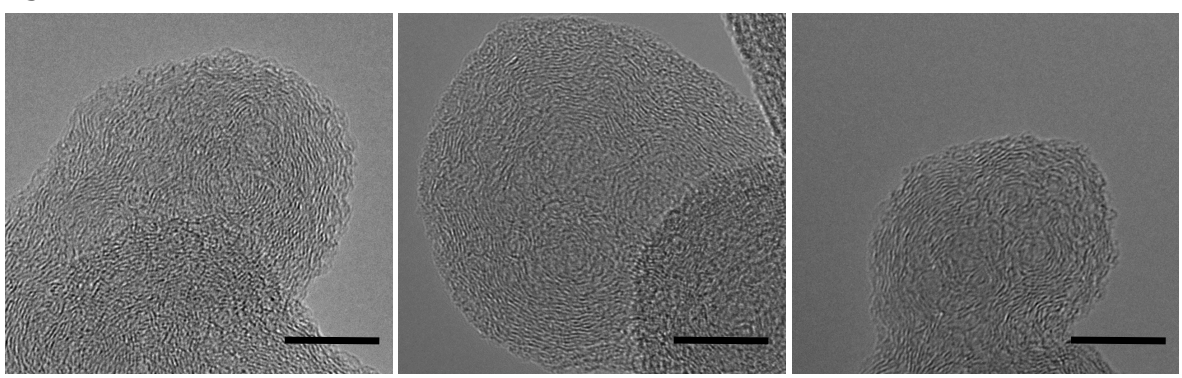

Figure A.10: Representative HRTEM images of soot particles sampled in the first half of the flame. The scale bar corresponds to $10 \mathrm{~nm}$. 
$31 \mathrm{~mm}$ HAB
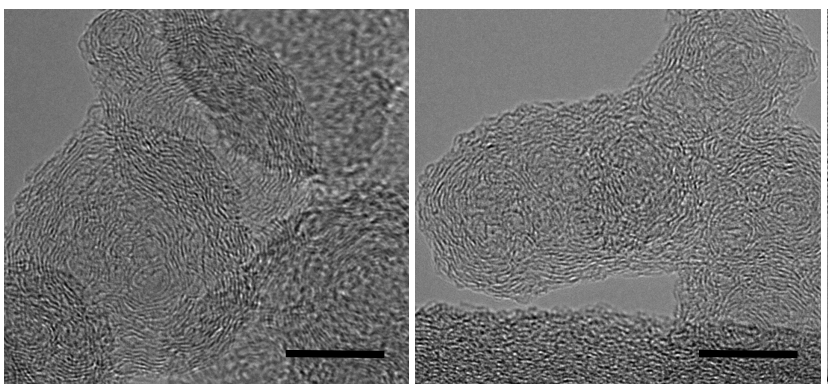

37 mm HAB
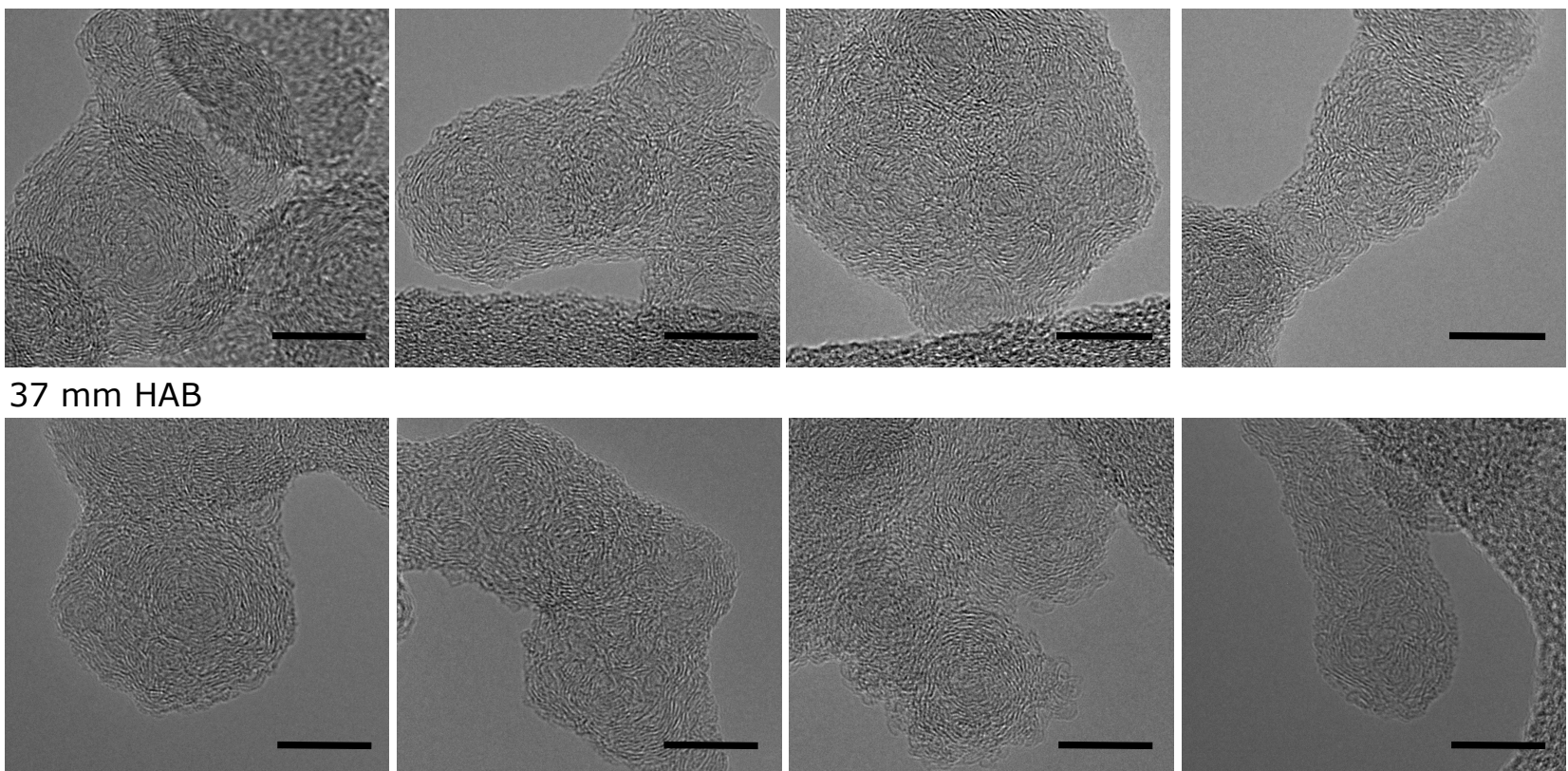

\section{$43 \mathrm{~mm}$ HAB}
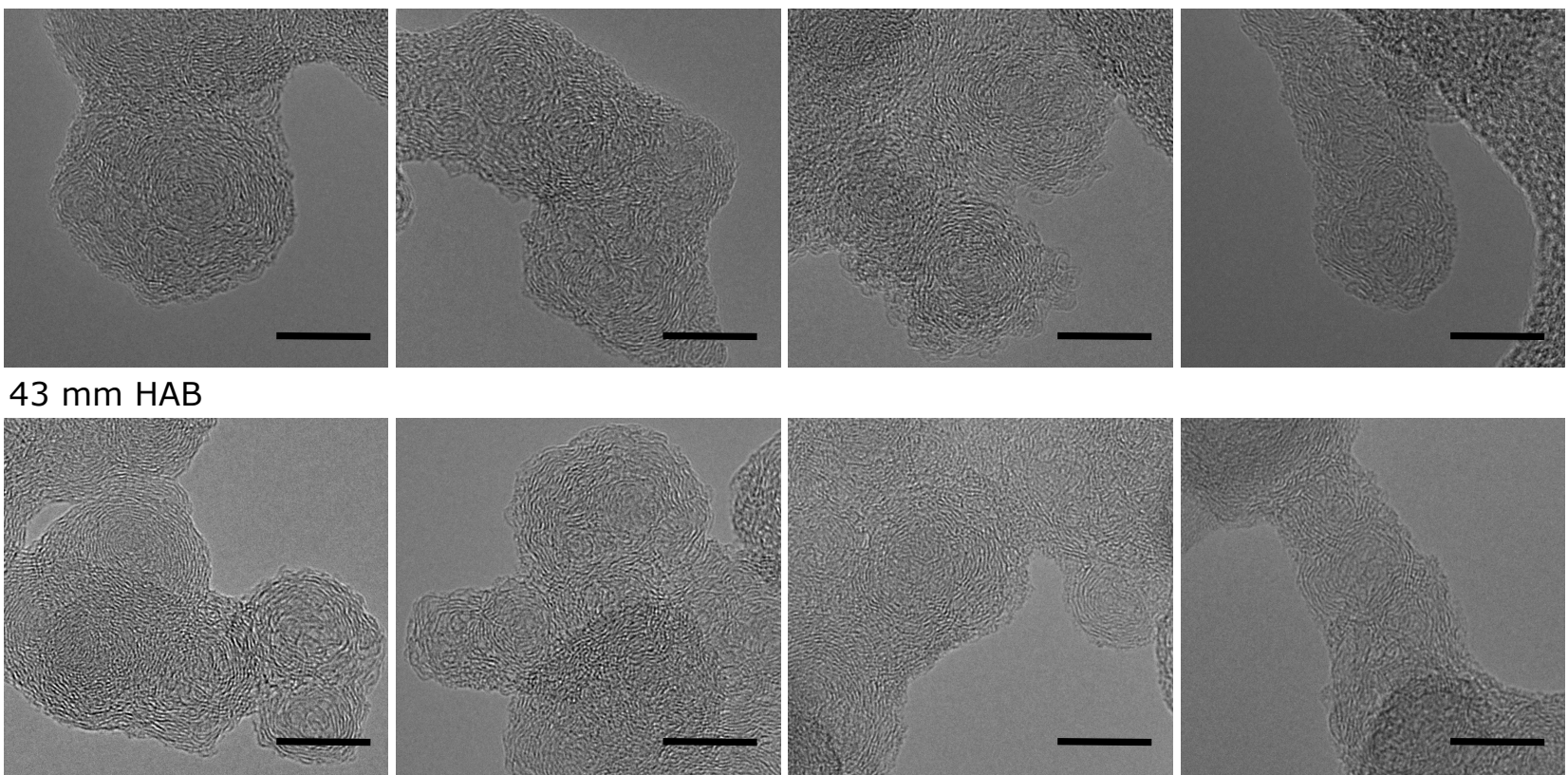

$49 \mathrm{~mm} H A B$
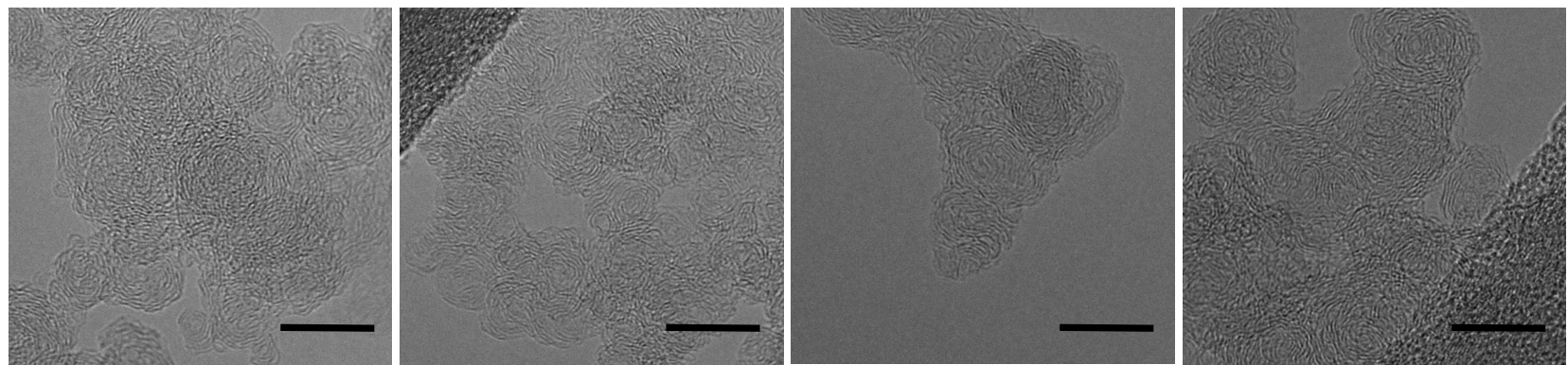

Figure A.11: Representative HRTEM images of soot particles sampled in the top of the flame. The scale bar corresponds to $10 \mathrm{~nm}$. 